\title{
Identification of the Factors Responsible for the Selective in vitro Cytotoxic Activity of Isoprenylated Coumarin Derivatives under Nutrient-deprived Conditions
}

\author{
Hong Zhang ${ }^{1}$, Ronghao Zhou ${ }^{1}$, Maria Jun${ }^{1}$, Alyssa F. Bacay ${ }^{1}$, Katherine Eyring ${ }^{1}$, Andrew Webb ${ }^{2}$, Dora \\ Carrico-Moniz ${ }^{1, \mathbb{}}$ \\ 1. Department of Chemistry, Wellesley College, Wellesley, Massachusetts 02481, USA \\ 2. Department of Biological Sciences, Wellesley College, Wellesley, Massachusetts 02481, USA \\ $\bowtie$ Corresponding author: Dr. Dora Carrico-Moniz. dcarrico@wellesley.edu
}

(C) Ivyspring International Publisher. Reproduction is permitted for personal, noncommercial use, provided that the article is in whole, unmodified, and properly cited. See http://ivyspring.com/terms for terms and conditions.

Received: 2015.07.14; Accepted: 2015.10.30; Published: 2016.01.01

\begin{abstract}
Pancreatic cancer is one of the most devastating forms of human cancer. The lack of effective clinical treatments for pancreatic cancer has led to one of the lowest five-year survival rates among all cancers. Recently, our laboratory has developed a novel series of isoprenylated coumarin derivatives that have exhibited anti-pancreatic cancer activity exclusively under nutrient-deprived conditions. In this study, we report the effect of the various cell culture medium components on the preferential cytotoxicity of our lead isoprenylated coumarin compound against the pancreatic adenocarcinoma cell line PANC-1. In particular, our findings show a clear link between observed cytotoxicity and glucose deprivation, suggesting that our compound targets a salvage pathway when glycolysis is no longer an option for cancer cell survival. The cytotoxicity of our lead compound was also examined in vitro against two other pancreatic cancer cell lines, BxPC-3 and Capan-2 under both nutrient-rich and nutrient-deprived conditions.
\end{abstract}

Key words: isoprenylated coumarin derivatives, anti-pancreatic cancer

\section{Introduction}

Although not the most prevalent of human malignancies, a unique combination of physiology, anatomy and biology leads to an extremely poor prognosis for all but a few patients diagnosed with pancreatic ductal adenocarcinoma (PDAC). Pancreatic cancer is known for its early metastasis and aggressive invasion of surrounding tissues. Due to the lack of early detection methods and a paucity of recognizable symptoms, patients are usually diagnosed at late tumor stages without surgical therapy options. ${ }^{1}$ Approximately $80 \%$ of pancreatic cancer patients present with locally advanced, non-resectable or distant metastatic disease. Even for patients diagnosed with surgically resectable local disease, the 5-year relative survival rate is less than $30 \%$. When aug- mented with adjuvant chemoradiotherapy, typically only $3 \%-4 \%$ can achieve long-term cure. ${ }^{2}$ In addition, pancreatic cancer is highly resistant to conventional systemic chemotherapies such as gemcitabine, paclitaxel, 5-fluorouracil, leucovorin and platinum-based drugs. ${ }^{3,4}$ This chemoresistance is a function of the desmoplastic architecture of pancreatic tumor stroma which contributes to exaggerated hypovasculature. 4 This weak blood perfusion applies equally to nutrients and leads to an aggressive biology for PDAC whereby these tumor cells can survive under extreme nutrient deprivation. Despite recent advances in genotyping and development of matched targeted therapeutics that demonstrate impressive efficacy in vitro, these have not to-date provided 
worthwhile advancement in clinical strategies. ${ }^{5}$ Unfortunately, currently available therapies provide at best only marginal improvement in median survival, let alone a guarantee of the complete eradication of pancreatic cancer.

In 2000, Izuishi and coworkers reported a study comparing the survival of pancreatic cancer cells and normal human fibroblasts in media lacking glucose, amino acids and serum, to mimic the nutrient deprivation conditions encountered in vivo. ${ }^{6}$ Four pancreatic cancer cell lines, including PANC-1, AsPC-1, BxPC-3, and KP-3, were shown to survive for $48 \mathrm{~h}$ under nutrient deficiency, whereas normal fibroblasts died within $24 \mathrm{~h}$ under the same conditions. ${ }^{6}$ Since normal tissues seldom encounter nutrient deprivation, the austerity of pancreatic cancer cells has become a potential novel biochemical target for cancer therapy.

Significant effort has been invested in searching for anti-austerity agents that selectively target pancreatic cancer cells under nutrient-deprived conditions. In 2006, a coumarin-based natural product, angelmarin (1, Figure 1), was isolated from the root of the Japanese medicinal plant, Angelica pubescens. The 23-carbon structure contains a columbianetin (2, Figure 1) core and a $p$-hydroxycinnamoyl group (blue, Figure 1) connected via an ester linkage. Angelmarin was found to exhibit cytotoxicity against PANC-1 cells preferentially under nutrient-deprived conditions, inducing $100 \%$ cell death at a concentration of $0.01 \mu \mathrm{g} / \mathrm{mL}$ within 24 h. $^{7}$
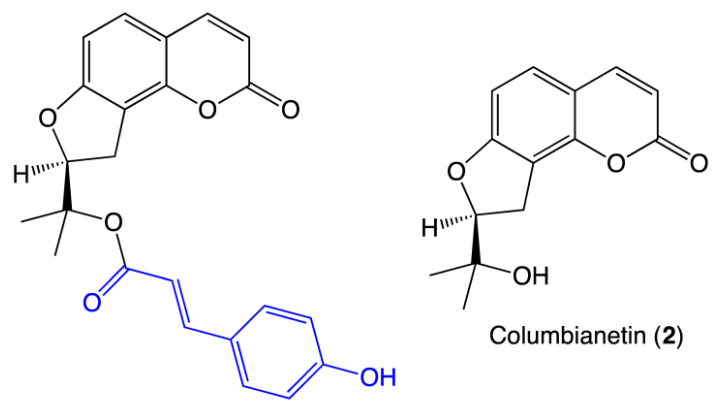

Angelmarin (1)
The core coumarin (3) structure of angelmarin (1) (1, Figure 1 and 3, Figure 2) is found in a number of pharmacologically active compounds and hydroxycoumarin derivatives in particular have been shown to exhibit promising antitumor, anti-flammatory and anti-viral effects. ${ }^{8}$ Intrigued by the selective cytotoxicity of angelmarin against pancreatic cancer cells under nutrient-deprived conditions and the frequent occurrence of coumarins in natural compounds, our laboratory launched structure-activity relationship (SAR) studies based on the core coumarin structure of angelmarin.

In 2011, our group reported the discovery of a novel geranylgeranylated ether coumarin derivative (4, Figure 2) that was found to induce PANC-1 cell death at a concentration of $6.25 \mu \mathrm{M}$ within $24 \mathrm{~h}$, with preferential cytotoxicity under nutrient-deprived conditions. ${ }^{8}$ Since this discovery, a library of other isoprenylated coumarin derivatives with systematic variations in the tail length (5, 10 or 15 carbons) and substitution position on the coumarin scaffold (at 3-, 6- or 7-position) has been completed. ${ }^{9}$ The 6-substituted farnesylated ether coumarin derivative (5, Figure 2) displayed the highest cytotoxic activity with an $\mathrm{LC}_{50}$ value of $4 \mu \mathrm{M}$ and induced apoptosis-like morphological changes in PANC-1 cells after a 24-hour incubation, making this isoprenylated ether coumarin our most promising lead compound. ${ }^{9}$

In order to better understand the preferential cytotoxicity of our anti-proliferative coumarin derivatives, we have begun studies to probe the cellular mechanism of action of these compounds. For these studies, we selected compound 5 because of its potent and selective cytotoxicity against PANC-1 cells under nutrient-deprived conditions. The studies presented herein explore the effect of several cell culture medium components on the cytotoxic activity of $\mathbf{5}$. The cell growth inhibition activity of $\mathbf{5}$ against two additional pancreatic cancer cell lines, BxPC-3 and Capan-2, is also reported.

Figure 1. Structures of angelmarin and columbianetin.
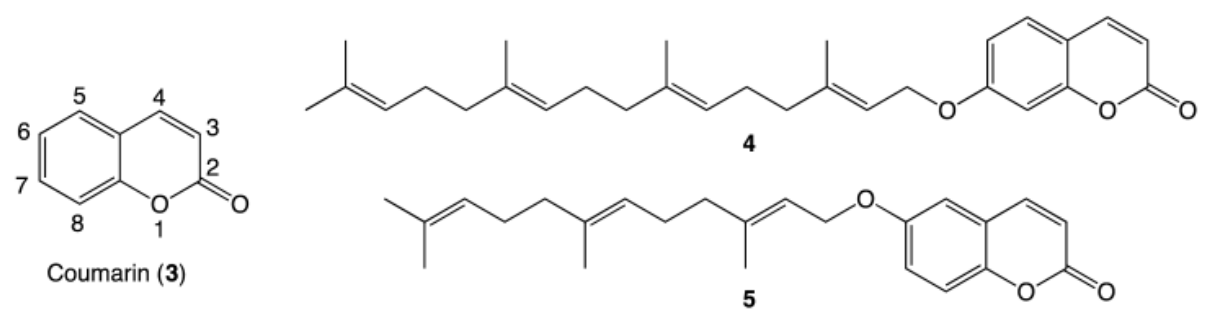

Figure 2. Structures of coumarin moiety (3) with labeled positions, a geranylgeranylated coumarin derivative $\mathbf{4}$ and a farnesylated coumarin derivative $\mathbf{5}$. 


\section{Materials and Methods}

\section{Cells and Preparation of Dulbecco Modified Eagle's Medium (DMEM)}

Human pancreatic cancer cell lines, PANC-1, BxPC-3, and Capan-2 were cultured in Dulbecco Modified Eagle's Medium (DMEM). To prepare DMEM, one bottle of DMEM powder (Sigma-Aldrich) was dissolved in $800 \mathrm{~mL}$ of HPLC grade water. Sodium bicarbonate solution $(49.1 \mathrm{~mL})$ and antibiotic-antifungal solution $(10 \mathrm{~mL}, 100 \mathrm{x})$ were added to the mixture. The volume was brought to $900 \mathrm{~mL}$ and the solution was adjusted to a $\mathrm{pH}$ between 7-7.4. Heat-inactivated fetal bovine serum (FBS, $100 \mathrm{~mL}$ ) was added to the neutralized solution and filtered via a $0.2-\mu \mathrm{m}$ Corning filter. The medium was stored at 4 ${ }^{\circ} \mathrm{C}$. Cells were passaged twice a week by trypsinization.

\section{Preparation of Nutrient-Deprived Medium (NDM), Nutrient-Rich Medium (NRM) and Special Media Conditions}

For all medium conditions, the following electrolytes and vitamin solution were added in concentrations as follows: $\mathrm{CaCl}_{2}\left(2 \mathrm{H}_{2} \mathrm{O}\right), 265 \mathrm{mg} / \mathrm{L}$; $\mathrm{Fe}\left(\mathrm{NO}_{3}\right)\left(9 \mathrm{H}_{2} \mathrm{O}\right), 0.1 \mathrm{mg} / \mathrm{L} ; \mathrm{KCl}, 400 \mathrm{mg} / \mathrm{L} ; \mathrm{MgSO}_{4}(7$ $\mathrm{H}_{2} \mathrm{O}$ ), $200 \mathrm{mg} / \mathrm{L} ; \mathrm{NaCl}, 6400 \mathrm{mg} / \mathrm{L} ; \mathrm{NaHCO}_{3}, 700$ $\mathrm{mg} / \mathrm{L} ; \mathrm{NaH}_{2} \mathrm{PO}_{4}, 125 \mathrm{mg} / \mathrm{L}$; phenol red, $15 \mathrm{mg} / \mathrm{L}$; HEPES buffer (25mM, pH 7.4); and MEM vitamin solution $(1 \mathrm{x} / \mathrm{L})$ (Life Technologies, Inc., Rockville, MD), which completed the preparation of the NDM. For NRM, additional nutrients were supplement at concentrations as follows: D-glucose, $1000 \mathrm{mg} / \mathrm{L}$; L-glutamine, $2 \mathrm{mM}$; MEM amino acids solution and MEM nonessential amino acids solution (Life Technologies, Inc.), $20 \mathrm{~mL}$ and $10 \mathrm{~mL}$ respectively for $1 \mathrm{~L}$ medium; FBS, $100 \mathrm{~mL}$ for $1 \mathrm{~L}$ medium. For all special media combinations, corresponding combinations of nutrients were added at concentrations identical to those in NRM. For media with dialyzed serum, the same concentration of dialyzed serum (Life Technologies, Inc.) was added as a replacement of FBS (100 $\mathrm{mL}$ for $1 \mathrm{~L}$ medium).

\section{Tumor Cell Culture Procedures}

To a cell-containing T-75 culture flask, a $2-5 \mathrm{~mL}$ aliquot of filtered trypsin-EDTA was added to detach the cells after the aspiration of DMEM and a PBS wash. The trypsin-containing flask was placed in the incubator $\left(37^{\circ} \mathrm{C}\right.$ and $\left.5 \% \mathrm{CO}_{2}\right)$ for $2-3$ minutes and then monitored under a microscope with $10 \mathrm{x}$ amplification. Detached cells were transferred to a $15 \mathrm{~mL}$ centrifuge tube and pelleted for 3 minutes at $1000 \mathrm{rpm}$. The supernatant of the resulting content was aspirated. The cell pellet was re-suspended thoroughly in the complete DMEM and transferred to an appropriately-labeled T-75 flask with additional DMEM to reach a final volume of $25 \mathrm{~mL}$.

\section{General Procedures of Cytotoxicity Assays}

In vitro cytotoxicity assay: Pancreatic cancer cells (PANC-1, BxPC-3 or Capan-2), were seeded in 96-well plates at a density of 23,000 cells per well and incubated in a fresh DMEM, (Sigma-Aldrich) at $37^{\circ} \mathrm{C}, 5 \%$ $\mathrm{CO}_{2}$ for $24 \mathrm{~h}$. After rinsing with PBS, cells were subjected to the addition of NRM, NDM, or special media conditions. Serially diluted solutions of synthesized compounds ( $5.5 \% \mathrm{v} / \mathrm{v}$ DMSO in NDM) were added to the cells up to a series of concentrations of $100 \mu \mathrm{M}, 50$ $\mu \mathrm{M}, 25 \mu \mathrm{M}, 12.5 \mu \mathrm{M}$ and $6.25 \mu \mathrm{M}$, followed by a $24 \mathrm{~h}$ incubation at $37{ }^{\circ} \mathrm{C}, 5 \% \mathrm{CO}_{2}$. Cell morphology was monitored under an inverted microscope. Cytotoxicity was assessed on PBS washed cells by the addition of fresh DMEM containing 10\% WST-8 cell counting reagent (Dojindo). Following a $3 \mathrm{~h}$ incubation at $37^{\circ} \mathrm{C}$, $5 \% \mathrm{CO}_{2}$, absorbance values were measured with a plate reader at $450 \mathrm{~nm}$, and cell viability was calculated using the equation:

$$
\begin{aligned}
\% \text { cell viability }= & \left\{\left[\mathrm{Abs}_{\text {test }}-\mathrm{Abs}_{\text {blank }}\right] /\left[\mathrm{Abs}_{\mathrm{control}}-\mathrm{Ab}-\right.\right. \\
& \left.\left.\mathrm{S}_{\text {blank }}\right]\right\}^{*} 100 \% .
\end{aligned}
$$

At least two replicate experiments were conducted for each medium condition reported, and similar results were obtained.

\section{Synthesis of 6-(((2E,6E)-3,7,11-trimethyldo- deca-2,6, 10-trien-1-yl)oxy)-2H-chromen-2-one} (5)

Compound 5 was synthesized as previously described. ${ }^{9}$

Briefly, to an oven-dried $100 \mathrm{~mL}$ round bottom flask prepared with a magnetic stirring bar, a rubber septum cover, and a nitrogen inlet, 6-hydroxycoumarin $(486.4 \mathrm{mg}, 3.0 \mathrm{mmol})$ and $4 \mathrm{~mL}$ of anhydrous $\mathrm{N}, \mathrm{N}$-dimethylformamide (DMF) were added. The solution was cooled to $0{ }^{\circ} \mathrm{C}$ in a salt-ice bath and sodium hydride $(120 \mathrm{mg}$ of $60 \%$ mineral oil suspension, $3.0 \mathrm{mmol}$ ) was added to the flask. The solution was then stirred at $0{ }^{\circ} \mathrm{C}$ for 30 minutes. Farnesyl bromide $(1.0 \mathrm{~mL}, 3.69 \mathrm{mmol})$ dissolved in $1 \mathrm{~mL}$ of anhydrous DMF was cooled to $0^{\circ} \mathrm{C}$ and added dropwise to the reaction flask through the rubber septum using a syringe. The reaction mixture was left stirring under nitrogen with warming to room temperature overnight and concentrated in vacuo. The desired product was obtained by column chromatography using a solvent system of $100 \%$ Hexanes, 20:1 Hexanes:Ethyl acetate, 15:1 Hexanes:Ethyl acetate, 10:1 Hexanes:Ethyl acetate, 7:3 Hexanes:Ethyl acetate, and 2:1 Hexanes:Ethyl acetate. The identity of the purified product was confirmed by NMR spec- 
troscopy ( $\left.{ }^{1} \mathrm{H}-\mathrm{NMR},{ }^{13} \mathrm{C}-\mathrm{NMR}\right)$ and high-resolution mass spectrometry (HRMS). ${ }^{1} \mathrm{H}-\mathrm{NMR}(300 \mathrm{MHz}$, $\left.\mathrm{CDCl}_{3}\right): \partial$ 1.60-1.76 $(12 \mathrm{H}), 1.96-2.12(8 \mathrm{H}), 4.56(\mathrm{~d}, 2 \mathrm{H}$, $\mathrm{J}=6 \mathrm{~Hz}), 5.09(\mathrm{~m}, 2 \mathrm{H}), 5.48(\mathrm{t}, 1 \mathrm{H}), 6.43(\mathrm{~d}, 1 \mathrm{H}, \mathrm{J}=9 \mathrm{~Hz})$, 6.92-7.66 (4H); ${ }^{13} \mathrm{C}-\mathrm{NMR}\left(75 \mathrm{MHz}, \mathrm{CDCl}_{3}\right): \partial$ 15.93, $16.29,17.70,25.71,26.29,27.04,39.53,39.69,109.75$, $117.00,117.83,119.14,123.31,123.77,128.33,131.38$, 135.56, 141.96, 143.27, 148.40, 155.33, 161.05. HRMS (CI) Calcd. for $\mathrm{C}_{24} \mathrm{H}_{31} \mathrm{O}_{3}$ : 367.22733; found: 367.22801.

\section{Results and Discussion}

Compound 5 was prepared via a Williamson ether synthesis using farnesyl bromide $\mathbf{6}$ and 6-hydroxycoumarin sodium alkoxide 7 pre-generated by treating the hydroxycoumarin with sodium hydride (Figure 3). The desired compound was purified by flash column chromatography and was thoroughly characterized by ${ }^{1} \mathrm{H}$ - and ${ }^{13} \mathrm{C}-\mathrm{NMR}$ spectroscopy and High Resolution Mass Spectrometry.

Compound 5 was tested in vitro for its cytotoxic activity against PANC-1 cells under different medium conditions (Figure 4). Our previous studies have shown that $\mathbf{5}$ exhibits selective cytotoxicity against PANC-1 cells under nutrient-deprived conditions with no activity observed under nutrient-rich conditions. ${ }^{9}$ The role of three essential medium components, amino acid (AA), glucose (Glu) and serum (Ser) were systematically evaluated to account for the difference in the cytotoxic activity of $\mathbf{5}$ observed under nutrient-rich vs nutrient-deprived conditions. To better focus on the contribution of glucose to the viability of PANC-1 cells in the presence of 5 , we have also run assays in the presence of dialyzed serum (Dia Ser). Cell culture medium lacking all three nutrients (nutrient-deprived medium, NDM) and medium containing all three nutrients (nutrient-rich medium, NRM) were selected as controls. The survival of PANC-1 cells was examined within $24 \mathrm{~h}$ after the exposure to 5 by using the WST- 8 reagent to assay for cell viability. Media compositions that demonstrate $<25 \%$ cell death in the presence of $\mathbf{5}$ are designated "Inactive" and media compositions that demonstrate $>25 \%$ cell death in the presence of $\mathbf{5}$ are designated "Active."

In this study, exposure of PANC-1 cells to 100 $\mu \mathrm{M}$ of compound 5 for 24 hours led to complete cell death in NDM and the cell culture medium combina- tion of NDM and AA, whereas less than $40 \%$ cell death was observed under all other medium conditions examined (Figure 5). Thus, the link between observed cytotoxicity and glucose deprivation appears to be significant. For example, when PANC-1 cells are deprived of glucose or very low levels of glucose are present, complete or almost complete cell death is observed upon 24-hour exposure to $100 \mu \mathrm{M}$ of compound 5. The relatively unimportant role of the presence of AA in the observed cytotoxic activity is highlighted by the medium combination of NDM and AA (i.e., lacking both serum and glucose), which displayed a similar effect on the cytotoxicity of $\mathbf{5}$ as pure NDM.

The cytotoxicity of $\mathbf{5}$ was also investigated in vitro against two other pancreatic cancer cell lines, BxPC-3 and Capan-2 (Figure 6). Similar to PANC-1, both cell lines exhibited a preferential sensitivity to compound 5 only under nutrient-deprived conditions (NDM), with $\mathrm{LC}_{50}$ values of $5 \mu \mathrm{M}$ for both cell lines (Table 1).

Table 1. Preferential cytotoxicity of $\mathbf{5}$ against all three pancreatic cancer cell lines.

\begin{tabular}{lll}
\hline & $\mathrm{LC}_{50}(\mu \mathrm{M})$ in NDM & $\mathrm{LC}_{50}(\mu \mathrm{M})$ in NRM \\
\hline PANC-1 & 9 & $>100$ \\
BxPC-3 & 5 & $>100$ \\
Capan-2 & 5 & $>100$ \\
\hline
\end{tabular}

Numerous anti-austerity agents have been reported to possess preferential cytotoxicity against PANC-1 under nutrient-deprived conditions. Key nutrients were examined to obtain information about the sensitivity of PANC-1 cells to other potential anticancer agents including troglitazone ${ }^{6}$, LY294002 ${ }^{6}$, kigamicin $\mathrm{D}^{10}$, pyrvinium pamoate ${ }^{11}$, arctigenin ${ }^{12}$, and damnacanthal. ${ }^{13}$ Among all compounds, troglitazone induced necrotic PANC-1 cell death under the depletion of glucose and serum. LY294002 exhibited cytotoxicity against PANC-1 cells via apoptosis when amino acid was depleted. Kigamicin D, pyrvinium pamoate and arctigenin induced necrotic PANC-1 cell death under glucose deprivation. However, when PANC-1 cells were exposed to damnacanthal, it was observed that the lack of serum was key to obtain cytotoxicity.

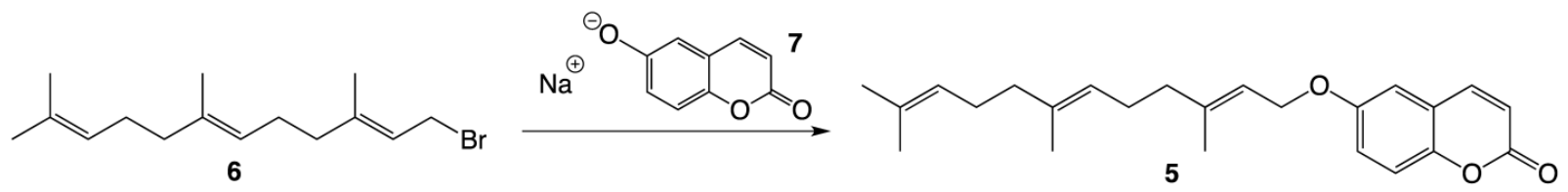

Figure 3. Synthesis of farnesylated ether coumarin $\mathbf{5}$ 


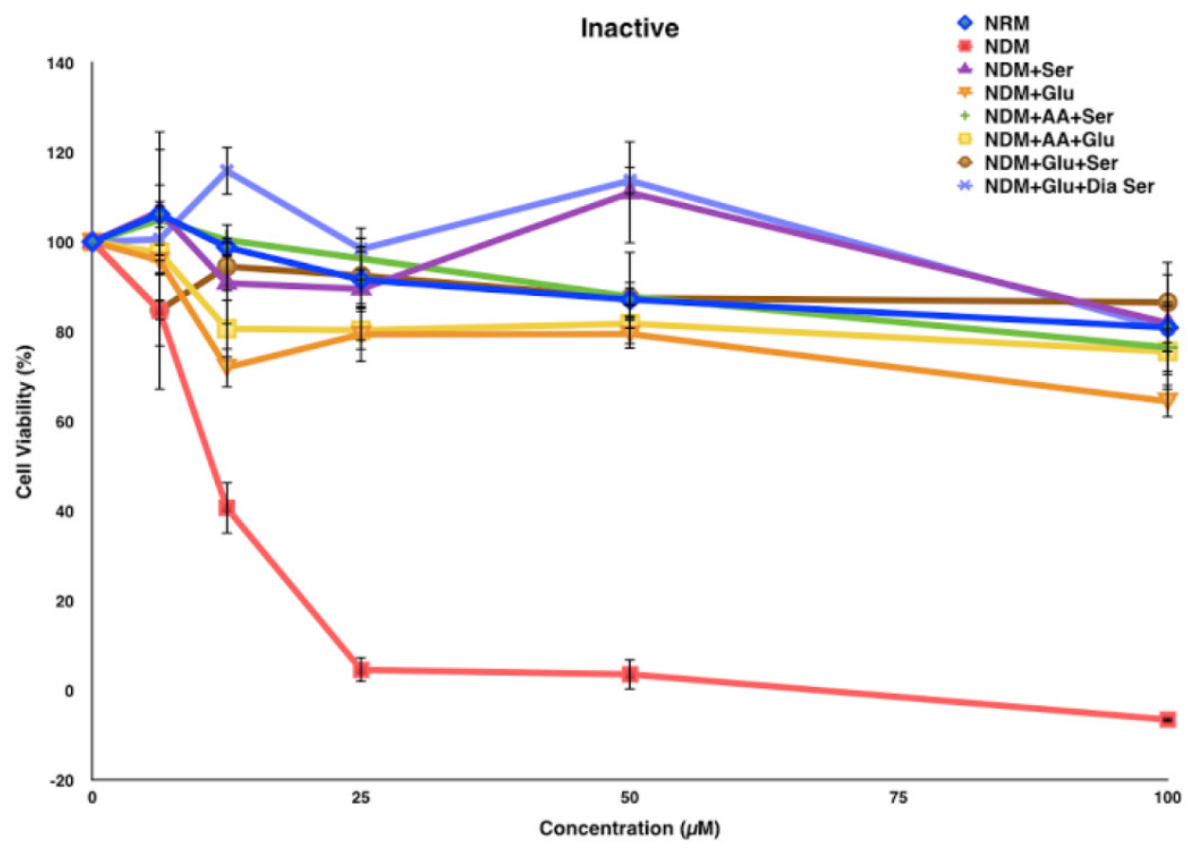

A.

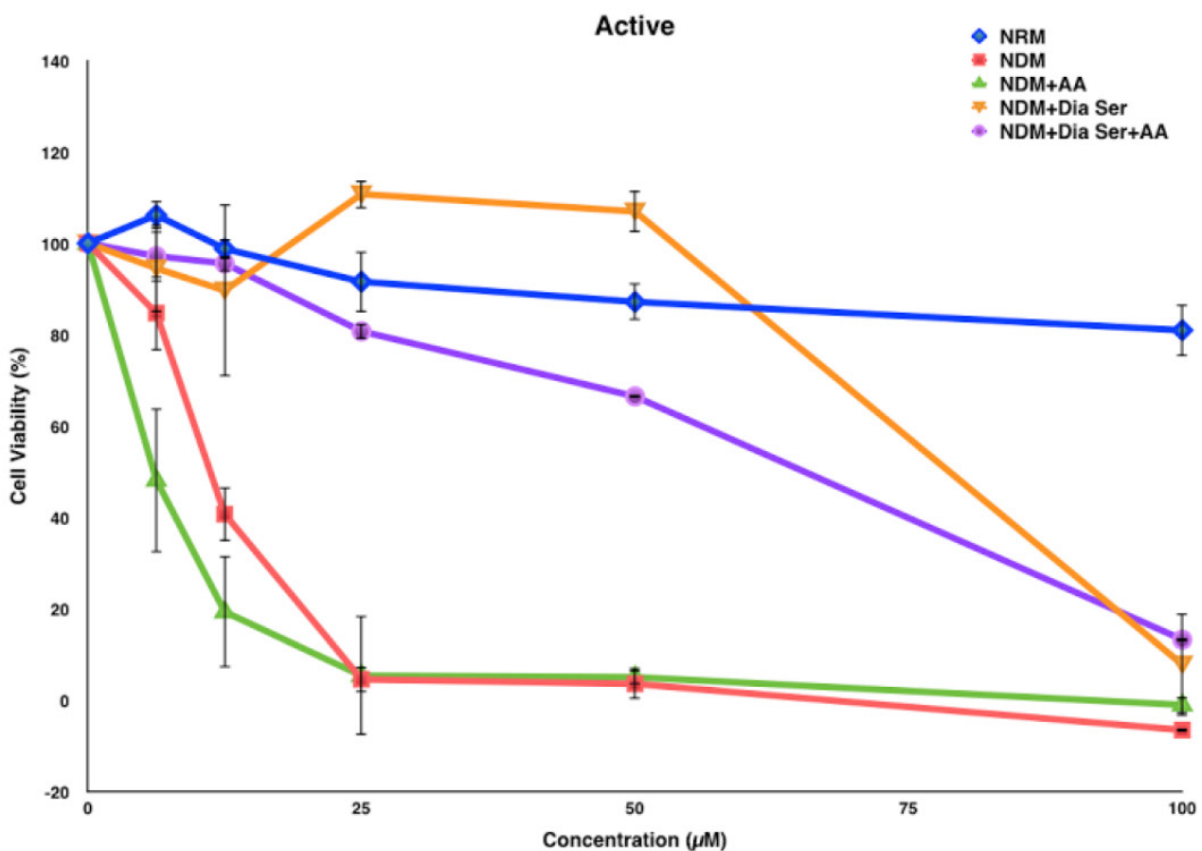

B.

Figure 4. Survival of PANC-1 cells under different cell culture medium conditions after $24 \mathrm{~h}$ incubation with compound 5 . All cell viabilities are means \pm SEM, $n=3$. Replicate experiments were performed and similar values were obtained. Concentrations of compound $\mathbf{5}$ investigated were $6.25,12.5,25,50$ and $100 \mu \mathrm{M}$. A. Media compositions that demonstrate $<25 \%$ cell death in the presence of $\mathbf{5}$ are designated "Inactive." B. Media compositions that demonstrate $>25 \%$ cell death in the presence of $\mathbf{5}$ are designated "Active." 


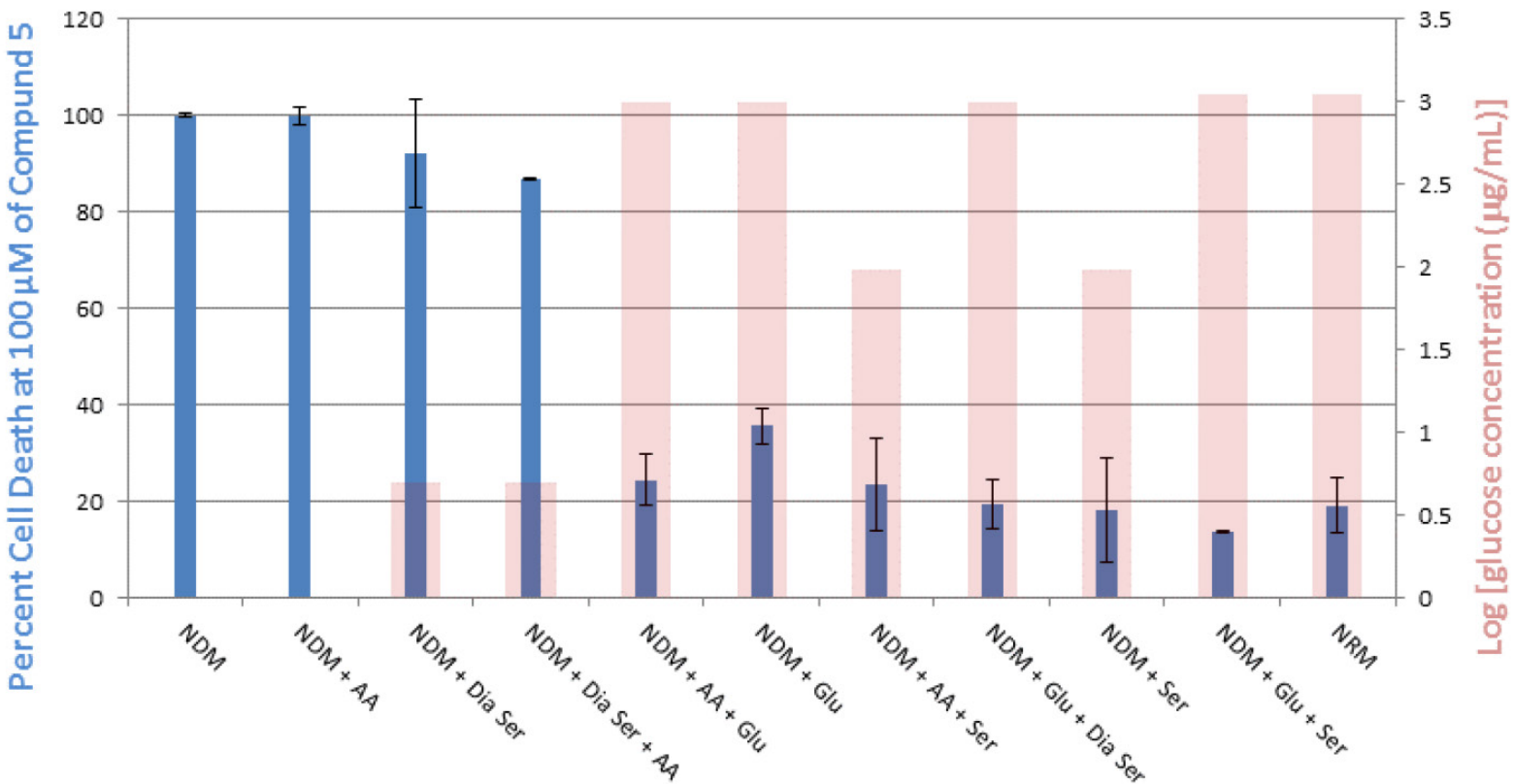

Media Components

Figure 5. Percent PANC-1 cell death upon exposure for $24 \mathrm{~h}$ to $100 \mu \mathrm{M}$ of compound $\mathbf{5}$ in cell culture media combinations of various nutrient components (glucose, amino acid, serum and dialyzed serum). All experiments were performed in triplicate, and the results are shown as means \pm SEM, $n=3$. The final concentration of glucose $(\mu \mathrm{g} / \mathrm{mL})$ in each medium, plotted on a log scale, is overlayed with the corresponding viability histogram.

BxPc-3

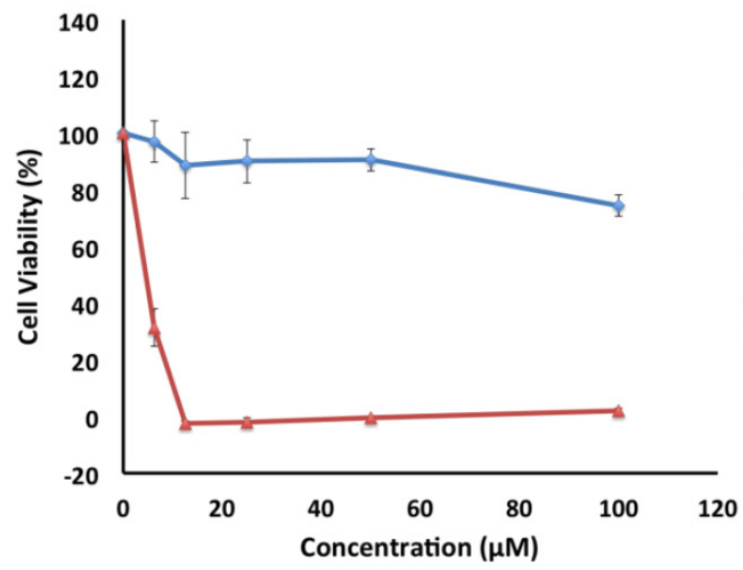

Capan-2

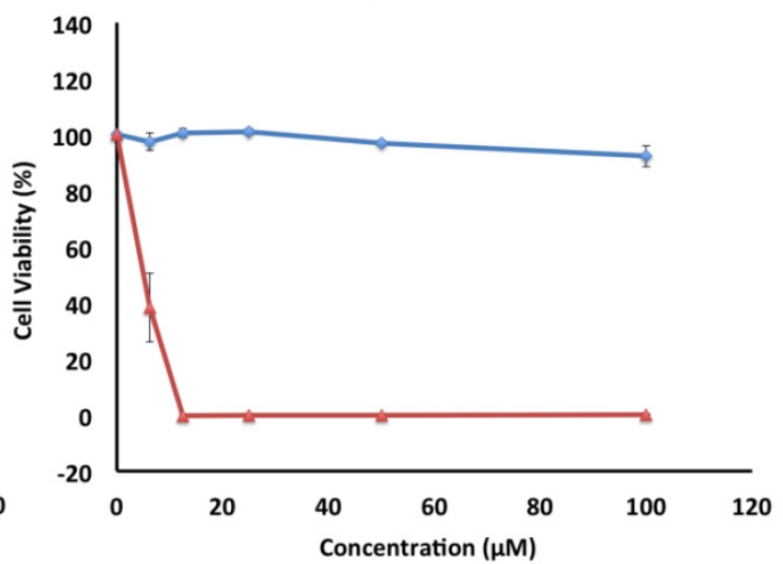

Figure 6. Survival of BxPC-3 and Capan-2 cells under nutrient-deprived conditions (red) and nutrient-rich conditions (blue) after $24 \mathrm{~h}$ incubation with compound 5. Compound 5 showed preferential cytotoxicity with $\mathrm{LC}_{50}$ values of $5 \mu \mathrm{M}$ against both cell lines. All cell viabilities are means of \pm SEM, $n=3$. Replicate experiments were performed and similar values were obtained. Concentrations of compound $\mathbf{5}$ investigated were $6.25,12.5,25,50$ and $100 \mu \mathrm{M}$.

Our data suggest that glucose may be the key component linked to the activity of compound 5 . It has been established for some time that cancer cells activate an altered metabolic regime that emphasizes the use of glycolysis over oxidative phosphorylation, classically referred to as the Warburg effect.14 Our observations would suggest that while glucose is plentiful even in supplemented NDM or NDM containing serum, compound $\mathbf{5}$ is less cytotoxic, presumably because of metabolic reorganization. How- ever, in the absence of serum or when the supply of glucose is limited by the addition of dialyzed serum to NDM, compound 5 becomes increasingly effective. This would imply that the efficacy of $\mathbf{5}$ targets a salvage pathway when glycolysis is less critical for cancer cell survival. The regulated cytological degradation known as autophagy is characteristically a part the biology of cancer cells and provides a mechanism by which cells can obtain essential nutrients from the dissolution of endogenous reservoirs (e.g., mitochon- 
dria). Interestingly, autophagy has been demonstrated to be integral to the survival of PDAC cells such as PANC-1 in the presence of chemotherapeutic drugs such as gemcitabine and 5 '-fluorouracil. ${ }^{15}$ With respect to the correlation between glycolytic dependency and autophagy, it is of note that (see Figure 4) under limited glucose availability (NDM + Dia Ser and NDM + Dia Ser + AA), compound 5 only becomes fully effective at higher concentrations. We interpret this as indicative of autophagy "exhaustion." It has not escaped our attention that the structure of $\mathbf{5}$ is in some regards similar to known inhibitors of autophagy (e.g., chloroquine). Autophagy as a therapeutic target has been explored extensively of late ${ }^{16}$, both from the standpoint of inhibition ${ }^{15}$, and hyper-stimulation ${ }^{17}$ at least in PANC-1 cells. The anti-proliferative activity displayed by compound $\mathbf{5}$ against the two other PDAC cell lines, BxPC-3 and Capan-2, in this study hint at a broad utility for this coumarin derivative. Since autophagy is of such prime importance to the progression of pancreatic tumors, the hallmark of which is extreme physiological stress, we are presently investigating our hypothesis that the mode of action of $\mathbf{5}$ is via an inhibition of autophagy.

\section{Acknowledgments}

This work was supported in part by a faculty award grant from Wellesley College. H.Z. was supported by a Jerome A. Schiff Fellowship award from Wellesley College.

\section{Competing Interests}

The authors have declared that no competing interest exists.

\section{References}

1. Asuthkar S, Rao JS, Gondi CS. Drugs in preclinical and early-stage clinical development for pancreatic cancer. Expert Opin Invest Drugs. 2012; 21(2): 143-152.

2. Roy R, Maraveyas A. Chemoradiation in pancreatic adenocarcinoma: a literature review. Oncologist. 2010; 15(3): 259-269.

3. Arumugam $\mathrm{T}$, Ramachandran V, Fournier KF, Wang $\mathrm{H}$, Marquis $\mathrm{L}$, Abbruzzese JL, Gallick GE, Logsdon CD, McConkey DJ, Choi W. Epithelial to Mesenchymal Transition Contributes to Drug Resistance in Pancreatic Cancer. Cancer Res. 2009; 69(14): 5820-5828.

4. Yu M, Tannock Ian F. Targeting Tumor Architecture to Favor Drug Penetration: A New Weapon to Combat Chemoresistance in Pancreatic Cancer? Cancer Cell. 2012; 21(3): 327-329.

5. Ryan DP, Hong TS, Bardeesy N. Pancreatic Adenocarcinoma. New Eng J Med. 2014; 371(11): 1039-1049.

6. Izuishi K, Kato K, Ogura T, Kinoshita T, Esumi H. Remarkable tolerance of tumor cells to nutrient deprivation: possible new biochemical target for cancer therapy. Cancer Res. 2000; 60(21): 6201-7.

7. Awale S, Nakashima EMN, Kalauni SK, Tezuka Y, Kurashima Y, Lu J, Esumi $\mathrm{H}$, Kadota S. Angelmarin, a novel anti-cancer agent able to eliminate the tolerance of cancer cells to nutrient starvation. Bioorg Med Chem Lett. 2006; 16(3): 581-583.

8. Devji T, Reddy C, Woo C, Awale S, Kadota S, Carrico-Moniz D. Pancreatic anticancer activity of a novel geranylgeranylated coumarin derivative. Bioorg Med Chem Lett. 2011; 21(19): 5770-5773.

9. Jun M, Bacay AF, Moyer J, Webb A, Carrico-Moniz D. Synthesis and biological evaluation of isoprenylated coumarins as potential anti-pancreatic cancer agents. Bioorg Med Chem Lett. 2014; 24(19): 4654-4658. b) Carrico-Moniz D, inventor; Coumarin Derivatives for Cancer Therapy. United States patent US
14/214,399. 2014 Mar 14. c) Carrico-Moniz D, inventor. Coumarin Derivatives for Cancer Therapy. United States patent US 14/213,181. 2014 Mar 14.

10. Lu J, Kunimoto S, Yamazaki Y, Kaminishi M, Esumi H. Kigamicin D, a novel anticancer agent based on a new anti-austerity strategy targeting cancer cells' tolerance to nutrient starvation. Cancer Sci. 2004; 95(6): 547-552.

11. Esumi H, Lu J, Kurashima Y, Hanaoka T. Antitumor activity of pyrvinium pamoate, 6-(dimethylamino)-2-[2-(2,5-dimethyl-1-phenyl-1H-pyrrol-3-yl) ethenyl]-1-methyl-quinolinium pamoate salt, showing preferential cytotoxicity during glucose starvation. Cancer Sci. 2004; 95(8): 685-690.

12. Awale S, Lu J, Kalauni SK, Kurashima Y, Tezuka Y, Kadota S, Esumi H. Identification of Arctigenin as an Antitumor Agent Having the Ability to Eliminate the Tolerance of Cancer Cells to Nutrient Starvation. Cancer Res. 2006; 66(3): 1751-1757.

13. Dibwe DF, Awale S, Kadota S, Tezuka Y. Damnacanthal from the Congolese Medicinal Plant Garcinia huillensis has a Potent Preferential Cytotoxicity against Human Pancreatic Cancer PANC-1 Cells. Phytother Res. 2012; 26: 1920-1926.

14. Ward PS, Thompson CB. Metabolic Reprogramming: A Cancer Hallmark Even Warburg Did Not Anticipate. Cancer Cell. 2012; 21(3): 297-308.

15. Hashimoto D, Blauer M, Hirota M, Ikonen NH, Sand J, Laukkarinen J. Autophagy is needed for the growth of pancreatic adenocarcinoma and has a cytoprotective effect against anticancer drugs. Eur J Cancer. 2014; 50(7): $1382-1390$.

16. Rubinsztein DC, Codogno P, Levine B. Autophagy modulation as a potential therapeutic target for diverse diseases. Nat Rev Drug Discov. 2012; 11(9): 709-730.

17. Ueda J, Athikomkulchai S, Miyatake R, Saiki I, Esumi H, Awale S. (+)-Grandifloracin, an antiausterity agent, induces autophagic PANC-1 pancreatic cancer cell death. Drug Des Devel Ther. 2014; 8: 39-47. 